\title{
Hypothermia With J (Osborne) Waves
}

David H. Spodick, MD, DSC

click an author to search for more articles by that author

A 40-year-old woman was found unconscious outside on a bitterly cold day; her body temperature was $83^{\circ} \mathrm{F}$. She was never able to provide a coherent history. J (Osborne) waves are seen at the QRS-T junctions, especially in leads II, III, aVF, and $\mathrm{V}_{2}-\mathrm{V}_{6}($ arrows) .

Osborne waves are characteristic of deep hypothermia, whether accidental (as seen here) or medically induced, in both humans and animals. A similar configuration may occur in severe hypercalcemia, nervous system disorders, and other conditions. Hypothermia affects both depolarization and repolarization, and the QT interval is prolonged. The mechanism of production of J waves is poorly understood, but they may be related to the transmural potential gradient at the onset of repolarization, which has been seen in vitro. $\mathrm{J}$-wave size has been related to the degree of hypothermia.

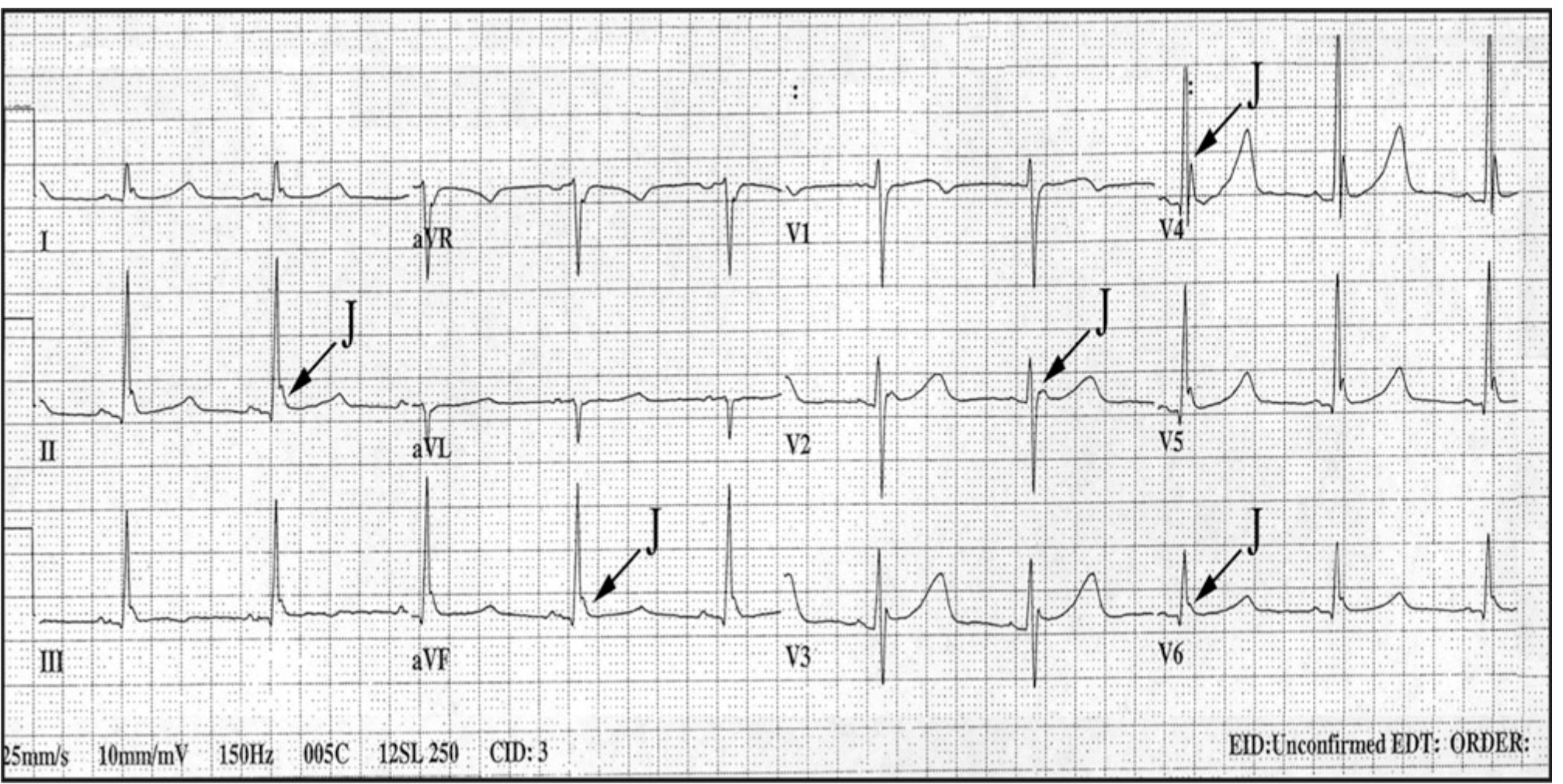

